\title{
Understanding Corruption and Corruptibility Through Experiments ${ }^{1}$
}

\section{Introduction}

Corruption remains an important policy concern in virtually all countries. Due to its secretive nature, the extent and pervasiveness of corruption is difficult to assess although examples of creditable assessment tools (e.g., CPI of TI (www.transparency.org; Treisman 2000), or the new V4 City Corruption Propensity Index of Transparency International CR (www.transparency.cz; Ortmann 2004) provide approximations that suggest that the available hard data (e.g., criminal convictions) are but the tip of the iceberg. Also, due to its secretive nature, it is difficult to identify what entices people to become corrupt.

Specifically, while the evidence suggests that low economic development, federal structure and short histories of experience with democracy and free trade all favor corruption on the macro-level (Treisman 2000), it is poorly understood what exactly, on the micro-level, the determinants of corruptibility are and what institutional arrangements could be used to fight (the causes of) corruption, if at all.

Among the specific questions in need of an answer are: How important are detection probabilities for bribe-giving and bribe-taking? How important are the threatened penalties? Are detection probabilities correctly perceived? Can the perception of detection probabilities be systematically manipulated (e.g., by going after high-visibility violators rather than routine violators)? Is corruptibility also a function of people's perception of the pervasiveness of corruption in society? Do efficiency wages, or loyalty premia, reduce the susceptibility of public officials (e.g., police or customs officers) to corruption? How about staff rotation? Are the leniency provisions in Czech law likely to accomplish what they are meant to accomplish? Is it really a good idea to distrust the $85 \%$ of police officers that seem be honest (even in the Czech Republic) by installing monitoring devices in their cars, and to switch to cash-less transactions rather than rely on whistle-blowers and hot-lines to go after the $15 \%$ of the force that are not? Is it really a good idea to have local detectives pursue small acts of bribery rather than some centralized police force that is not likely to know the alleged perpetrators? What do laws and regulations, in other words, have to look like if they are to stand a chance to effectively undermine »the tenacity of the past « (Treisman 2000, p. 438)?

Because of the secretive nature of corruption, these questions are difficult to answer. What one therefore typically sees is a trial-and-error approach to laws and regulations manifested in frequent legal and regulatory revisions through which authorities try to react to legislative and regulatory deficiencies that have become too obvious to ignore (e.g., see the frequent revisions of public procurement law in the Czech Republic). At best this legislative and regulatory process is informed by intuition and, maybe, examples from other countries.

1 This article draws heavily on Dusek, Ortmann \& Lizal (2005) which it shortens considerably but also updates. 


\section{Laboratory experiments to the rescue?}

Laboratory experiments (from here on simply experiments) have been used increasingly, and successfully, as economists' method of choice to understand a plethora of design and implementation problems: Experiments have, for example, been used to finetune auction mechanisms for spectrum auctions (Milgrom 2004; Klemperer 2004; Plott 1997; Plott \& Salmon 2004) and matching mechanisms in a variety of labor markets (Roth 2002).

Experiments allow us to control the behavior of subjects in ways that are typically not possible in the field. More importantly, experiments allow us to systematically manipulate the environment and the resulting behavior changes and hence to address the issue of causality in ways typically not possible in field contexts. It is simply less expensive to test alternative institutional arrangements (e.g., subtle differences in auction procedures for public procurement projects) in the experimental laboratory than in the laboratory of real life.

For these reasons, and because of the undeniable success of experiments elsewhere, experiments on corruption, corruptibility, and measures to fight them, seem prima facie self-suggesting. Interestingly, until a few years ago there were no such experiments. In fact, Dusek et al. (2005) reviewed the universe of such experiments which at the time of the writing of their article amounted to about a dozen. Before I discuss why experiments on corruption and corruptibility are rare, and what the future of such experiments might be, let me illustrate, and contextualize, the extant experiments by way of a few select examples.

\section{A brief review of experiments on corruption and corruptibility}

Dusek et al. (2005) categorize experiments on corruption and corruptibility, as those involving bilateral settings and unilateral settings. Corruption is, of course, almost by definition a three-player game involving a briber (the principal), a bribee (the agent, typically assumed to be some public official), and a third party (possibly, society), that is damaged by the bribe. That third party is, however, typically not an active player. Rather, it is a party negatively affected by the actions of the public official. If, for now, we ignore the welfarereducing externalities imposed on the third party, we can analyze corruption as a principalagent game that is problem-isomorph to »gift-exchange « games, or trust games, widely studied in the literature (e.g., Kreps 1990; Fehr \& Schmidt 1999; Bolton \& Ockenfels 2000; Charness \& Rabin 2003; Cox 2004; for a critical review see Gueth \& Ortmann 2006). The essence of such games is the interaction between two players, a principal and an agent each of which can engage in one of each actions. The principal can (not) trust that the agent will do what he promises to do (e.g., engage in the efficiency-enhancing action, that in the context we deal with here would be that an illegal action that promises benefits). A possible parameterization for such a principal-agent interaction is shown in Figure $1 .^{2}$ 
Figure 1 Principal

\begin{tabular}{llll}
\multirow{2}{*}{ Agent } & 1,1 & 0,0 & Do as promised \\
& $2,-1$ & 0,0 & Not
\end{tabular}

According to standard game theory (as canonized in prominent graduate textbooks such as Mas-Colell, Whinston \& Green 1995), the likely outcome of such a game played once - would be the undesirable outcome in the lower right corner. Note that game theory therefore predicts that acts of corruption are not likely to happen in situations that are modeled correctly by Figure 1. In essence, the outcome in the upper let corner requires trust (on the part of the briber, or principal) and reciprocity (on the part of the bribee, or agent) both of which are at odds with the assumptions of self-interest and rationality. That said, Figure 1 also suggests that repetition of such a game - supported by the reputational concerns on the part of the agent - might very well bring about the desirable (from the point of view of the principal and the agent) outcome in the upper left corner. And indeed, that is by and large the game-theoretic prediction for scenarios where agents repeatedly interact. ${ }^{3}$

The game-theoretic predictions for trust games of various forms have been tested experimentally $^{4}$ (Fehr, Kirchsteiger \& Riedl 1993; Fehr, Gaechter \& Kirchsteiger

2 The numbers in this payoff table denote utility or monetary units. Each pair of numbers is an ordered pair, with the first stating the payoff of the Row player (here the Agent) and the second stating the payoff the payoff of the Column player. For example, the action combination \{Not, Not\} leads to a payoff of zero for both participants reflecting in the current context that the efficiency enhancing action combination did not take place. In contrast, the efficiency-enhancing action combination (Do what promised, Trust) leads to a payoff of $» 1$ « for each of the two participants. The problem with that outcome is that - while it is efficiency-enhancing - it is not incentive-compatible: If the Principal were to trust, the Agent would have an incentive not to do what she promised, as she could clearly make herself better of not doing what she promised. (The Principal, according to standard game theory, would anticipate this reasoning and therefore not trust to start with; hence the gametheoretically predicted outcome, or »Nash equilibrium would be the action combination \{Not, Not\}.

3 Game-theoretically, one distinguishes between one-shot and finitely repeated games (which have the same outcome prediction) on the one hand and indefinitely repeated games on the other hand; in the current context we mean the latter. In essence, a game that is (indefinitely) repeated allows the players to capture repeatedly the payoffs in the upper left corner. For all reasonable discount factors, the sum total of these payoffs is larger than the occasional deviation payoff for the agent in the lower left corner.

4 An economics experiment typically takes place as follows: Potential participants are invited to come to a location such as a classroom or a (dedicated) computer lab. At that point they know relatively little about the experiment other than that is an economics experiment (a very important piece of knowledge, see Hertwig \& Ortmann 2001) and how much they can expect to earn. Once they are in the classroom or computer lab, they read (or, are being read) the instructions, and then - typically mediated through a computer program - make the kind of decisions described the Figure 1, or the various experiments described here. It is a key feature of an economics experiment that subjects do not answer hypothetical questions but that their decisions matter to them financially. (In most experiments subjects earn, on average, about $2-4$ times minimum wage.) 
1997; Engelmann \& Strobel 2004; Berg, Dickhaut \& McCabe 1995; Ortmann, Fitzgerald \& Boeing 2000; Cox 2004; for a critical review see Gueth \& Ortmann 2006), and - while there is some dispute about what the experimental data really show (e.g., Rigdon 2000; Dittrich \& Ziegelmeyer 2005; List forthcoming; see also Gueth \& Ortmann 2006) - there seems wide agreement that - in one-shot situations - trust and reciprocity bring about the outcome that's desirable from the perspective of the players more often than economic theory would have it.

Building on the basic paradigm of the trust game, Abbink, Irlenbusch, \& Renner [AIR] (2000) tested experimentally a »moonlighting game« with legally unenforceable types of contracts: A principal »hires « a moonlighter (the agent) to perform some task; he also provides the resources.

The moonlighter can either steal the resources or perform the task, thus generating an economic surplus (»efficiency gains «) which the agent can either share with the principal, or which he can pocket. In analogy to trust games, efficiency gains of that kind require a (non-binding) agreement to generate an economic surplus, and hence trust (on the part of the principal) and reciprocity (on the part of the agent). The novel feature in the game that AIR tested was an appended stage in which the moonlighter faced (nonrational) retribution if he did not reciprocate the trust. Game-theoretically, the appended retribution stage was constructed so as to not make a difference. Specifically, since retribution would be costly and bring about no direct benefit - telling the authorities that you had engaged in illegal activities would come at a net cost - a rational principal would not engage in it. The experimental results showed that this prediction was falsified. Summarizing very crudely, hostile actions were consistently punished (retribution!) while the friendly ones were less consistently rewarded (little reciprocity!) ${ }^{5}$

In a follow-up article (AIR, 2002), the same authors experimentally tested a bribery game. In the baseline or »pure reciprocity « treatment, the briber proposed to the bribee a deal. The bribee could decide whether to accept or reject the deal. If the bribee rejected the proposed deal, it did not materialize (and the briber got stuck with a small initiation fee). If the bribee accepted the proposed deal, it brought about (through the experimenter) a tripling of the briber's initial investment. Next the bribee had to choose one of two decisions, with the first decision benefiting the briber significantly more than the bribee, and the second decision benefiting the bribee somewhat more than the briber. As in the moonlighting game, this baseline treatment did not feature welfare-reducing externalities imposed on a third party. The possibility for retribution was also not offered. Still, more trust and reciprocity emerged - and hence more corruption and corruptibility - than standard game theory predicted.

The authors then tested experimentally the impact of externalities that impose a cost on a third party (the »negative externality « treatment), as well as the effects of a small probability of detection if they accepted the bribe (the »sudden death« treatment). These two »treatments « had the same game-theoretic prediction as the baseline »pure reciprocity « treatment. Namely, there should be no trust and there should be no recipro-

5 To those that know the relevant experimental literature (e.g., Guererk, Irlenbusch \& Rokkenbach 2006), the reported results do not come as surprise. 
city. All three treatments were conducted as 30 round »partners « treatments, meaning a subject was matched with one other person throughout. ${ }^{6}$ Technically, and for the gametheoretically uninitiated probably somewhat surprising, the game-theoretic prediction for these 30 rounds is the same as that of a one-shot game. Therefore, the game-theoretic prediction is that for a one-shot game rather than an (indefinitely) repeated game.

The results suggest that the behavior of bribers and bribees, maybe quite in line with intuition, is unaffected by the damage inflicted on a third party. (Here the third party was all the other participants in the experimental session, rather than some third party outside of the laboratory.) The threat of a drastic penalty (although extremely small in the experimental parameterization), decreased attempted bribes.

Abbink (2002) built on the bribery game in AIR (2002) but, rather than the third party being represented by all the other participants in the experimental session, the third party was now represented by additional subjects that performed a task (evaluating video clips) for which they were paid. Importantly, the wages these workers were given was either high or low relative to that of the public official, making the bribee (the public official) either better off or worse off (if he was not hit by sudden death). There was no treatment effect: whether the bribee received a relatively high or low wage did not affect significantly her or his reciprocity (to the giving of the briber). This observation is interesting in light of arguments - and empirical evidence (e.g., Van Rijckeghem \& Weder 2001) - which suggest that higher wages for public officials would make them more resistant to bribe offers.

Abbink (2004) built on the sudden-death treatment of AIR (2002) to study experimentally the corruption-reducing effects of staff rotation. Staff rotation is implemented by re-matching the participants in the experiment in each round (»strangers « treatment) rather than letting fixed pairs play all thirty interactions (»partners « treatment). The results are in line with intuition (but arguably contradicts earlier findings on partners/strangers treatments ${ }^{7}$ ) in that the number of offered transfers, i.e. bribery attempts, and their volume is cut by about half in the strangers treatment.

Frank \& Schulze (2000) and Schulze \& Frank (2003) conducted two experiments with members of a university student film club in Germany. Unlike in the experiments by Abbink and his collaborators, there was no reciprocal relationship between a bribee (the public official) and a briber who might choose to offer a bribe in order to induce the bribee to make a more favorable decision. Instead, a public official decided unilaterally how much money to »divert « from public funds, subject to the risk of being discovered and punished. Before watching a movie, each member was placed in the (fictitious) position of the manager of the club and presented with the following situation: The club needed to obtain some service from a private firm, and the manager had to choose a firm that would perform that service. Each subject was presented with offers

6 As opposed to a so-called strangers treatment which matches a players randomly, but quite possibly repeatedly, with all the other members in an experimental session.

7 Partners/strangers treatments were previously in public good experiments where the evidence, however, was rather mixed (see Andreoni \& Croson 2004). An important question for future research is therefore: Why does Abbink (2004) find these very strong strangers effect in (asymmetric) principal-agent games that do not exist in (symmetric) public good experiments. 
from several firms, which differed in (a) the price that the film club would have to pay and (b) the side payment (bribe) from the firm to the manager that the manager would keep for himself. (The higher the price, the higher was the bribe.) For example, if the manager was honest (= would not take a bribe) the club would have to pay only DM 20. If the manager was dishonest and, for example, took the maximum offered bribe of DM 144, the club would have to pay DM 200.

Participants indicated their secret choice on a form, the forms were collected, one of the forms was drawn, and the payoffs were made according to the subject's choice on the form that was drawn. The club would receive DM 200 minus the price chosen by the subject whose form was drawn, and that subject would receive the bribe that he opted for. Subjects were paid in private so that others could not observe the identity of the subject who may have harmed the club by his corrupt choice. Note that these experiments were unusual in that the public entity that would suffer from corruption was real: The experimenters could study corruption »as is « in the real world, while having other important variables under control.

The two key determinants of corruption investigated in these experiments were the officials' wages and the probability of detection. One half of the subjects were given a fixed payoff in addition to the possible bribe. Comparing these two groups allowed testing the hypothesis that higher wages of public officials lead to less corruption by inducing loyalty. One half of the subjects (both with the positive »wage« and zero wage) were also told that if their sheet were drawn and they accepted bribes, their payoff from the experiment would be nullified with a known probability.

Frank \& Schulze found that the relationship between officials' wages and corruption is non-trivial: When there was no risk of punishment, giving subjects an additional fixed payoff did not significantly reduce their proclivity to behave corruptly. Thus there was no evidence of the loyalty effect of wages. When punishment was possible, subjects receiving also the fixed payoff did choose lower bribes, which is consistent with the deterrence effect of higher wages. The risk of punishment produced the expected result on the other end of the distribution: the share of subjects choosing the maximum possible bribe fell from $28.8 \%$ to $12.6 \%$ when risk of punishment was introduced. A surprising result of this experiment was that the risk of punishment actually increased corruption: $9.4 \%$ of the population was honest when there was no risk of punishment while only $0.9 \%$ were honest when punishment was possible. Frank \& Schulze hypothesized that the introduction of monetary incentives reduced the intrinsic incentives to behave honestly, which has been observed in different experimental contexts (e.g., Gneezy \& Rusticchini 2000; see also Rydval \& Ortmann 2004).

\section{An experiment on leniency programs}

The effect of whistle-blowing on illegal behavior has already been analyzed in the context of anti-trust policy theoretically (e.g., Berentsen, Bruegger \& Loertscher 2003; Spagnolo 2004) and experimentally (Apesteguia, Dufwenberg \& Selten [ADS] 2004). The authorities wish to promote competition and discourage cartel deals. As cartel agreements are illegal, the members of a cartel have to rely on trust (and reciprocity) 
rather than on written agreements that might incriminate them. »Leniency « provisions essentially guarantee immunity to whistleblowers even if they were involved in the cartel agreement. ADS (2004) tested various implementations of leniency provisions meant to undermine cartel agreements. Specifically, they compared experimentally and in a Bertrand price undercutting set-up (e.g., Ortmann 2003) - three possible antitrust policies (all of which areb either already implemented in the US or discussed by the European Commission) with the ideal market outcome.

- Standard: all cartel members are punished

- Leniency: whistleblowers are granted partial or full immunity dependent on how many other firms also blow the whistle

- Bonus: the theoretically best approach in which the incentives to blow the whistle are increased through rewards that consist of a share of the fines non-reporting members of the cartel are made to pay

- Ideal: a competitive market scenario in which cartel formation is theoretically not possible and empirically unlikely

While the Ideal treatment is a one-stage game, the Standard, Leniency, and Bonus treatments are multi-stage games with a communication stage in which potential cartel members could hammer out agreements.

The key results were:

1. The market price in the Standard treatment was significantly higher than the market price in the treatment that induced competitive bidding;

2. The Leniency treatment led to significantly lower prices than those in the Standard treatment (there was no significant difference between this price and the one induced by competitive bidding), and (albeit, insignificantly) fewer cartels and more cartel members reporting;

3. The theoretically best approach (»Bonus «) did not live up to its billing: Market prices were significantly higher than in the Ideal or Leniency treatments and statistically not different from the results in the Standard treatment. Moreover, this environment led to the highest (although not significantly) number of cartel formations.

In a recent manuscript, Buccirossi \& Spagnolo (2006) analyzed theoretically the potentially perverse incentive effects of leniency provisions meant to combat corruption. In other words, they study leniency provisions in the context of trust games. (The key difference is that these games are sequential and asymmetric while the kind of Bertrand price undercutting set-up of ADS (2004) is simultaneous and symmetric.) Buccirossi \& Spagnolo (2006) show analytically that leniency provisions meant to combat corruption may well be a two-edged sword in that they can be used as a disciplining tool: A firm, for example, that has accepted a bribe but does not want to deliver on the implicit deal, can now - under certain conditions - be punished for not having paid. ${ }^{8}$ Whether indeed leniency provisions have these perverse incentive properties, and how they could be broken down, is difficult to assess in the field. Experiments are an obvious way to study them ${ }^{9}$.

8 Lizal \& Ortmann (2003) argue that a similar leniency mechanism is also a key provision of recent Czech anti-bribery legislation.

9 See Lizal \& Ortmann (2003) and Ortmann \& Richmanova (in prep). 


\section{Methodological issues}

As already indicated, experiments on corruption and corruptibility face - for all the acclaim that their internal validity warrants - serious questions about their external validity (Harrison \& List 2004). In fact, they probably face more reservations on this account than other laboratory experiments. Of particular concern are issues of »representative samples «, »representative stimuli «, and calibration of experiments on corruption and corruptibility and measures to fight them.

As regards representative samples, most experimental economists work with a convenience sample of subjects - traditional college students. This is true for all corruption studies reviewed above. In fact, as regards the articles and papers reviewed in Dusek et al. (2005) only Barr et al. (2003) employ non-traditional subjects (Ethiopean nursing students). A simple way to address this issue is to run control treatments with other, less convenient, but arguably more representative samples. Babicky \& Ortmann (2005), for example, recently conducted a battery of simple bargaining experiments (dictator, ultimatum, and trust games) with employees of Prague City Hall (which has a reputation of being among the most corrupt institutions in the Czech Republic. ${ }^{10}$ )

As regards representative stimuli, most studies follow the convention among experimental economists of using abstract laboratory environments. The bribery game in AIR (2002), for example, is not framed in terms of bribe-giving or bribe-taking (but see Abbink \& Hennig-Schmidt 2002), nor is the rotation experiment in Abbink (2004) framed as such, nor is the Falk \& Fischbacher (2000) experiment framed as a stealing experiment. In fact, only the experiments by Barr et al. (2003) and Frank \& Schulze (2000, 2003) feature aspects of real life in their set-ups. ${ }^{11}$ Babicky, Ortmann \& Semerak (in prep) have attempted to address some of the methodological issues (e.g., the issue of »asset legitimacy«, see Cherry, Frykblom \& Shogren 2002) but there should be no question that the issue of representative stimuli remains a severely understudied area.

Probably the toughest challenge to the external validity of experiments on corruption, corruptibility, and anti-corruption measures is the issue of calibration (i.e., to what extent the models underlying experimental tests are small-scale replicas of the real world, or the »field «). The results of Barr et al. (2003) exemplify the problem: Can the numbers - a 200 percent in wage increases affecting only $30 \%$ reduction in corruption - guide policy considerations in field contexts? Or, how do the clever but ultimately simplistic experiments of Frank \& Schulze (2000) and Schulze \& Frank (2003) translate into policy guidance, if at all?

10 Controlling for basic socio-demographic characteristics such as age and sex, and a measure of computer literacy/cognitive ability, our preliminary data analysis suggest that it is not the people per se that work in City Hall that are the problem but the institutional arrangements; a view supported by the results of the V4 City Corruption Propensity Index of Transparency International CR (www.transparency.cz; Ortmann 2004.)

11 That said, the absence of a loyalty effect of higher wages and the intrinsic motivation effect of the risk of punishment may have only limited external validity. In real-life situations, it is the principal himself who may induce loyalty or intrinsic motivations by offering higher wages or promising not to audit the agents. In the experiment, higher wage and risk of punishment were controlled by the experimenters, who were not connected with the principal (the film club) in a way that would meaningfully induce some loyalty. 


\section{Conclusion}

Even though the set of experiments on corruption and corruptibility is currently rather small, and even though there are tough methodological questions associated with these kinds of experiments, some reliable patterns have emerged from the experiments already conducted: For example, it seems clear that the welfare-reducing effects on third parties do not affect corrupt behavior (e.g., AIR 2002; Abbink 2002). This suggests that clean-hands campaigns or attempts to change the public sense of propriety through advertising in metro and trams are not likely to be successful in curbing corruption. Deterrence, it also seems clear, does work. Increasing the probability of detecting bribegiving and bribe-taking and the size of the punishment does by and large restrain corrupt behavior (e.g., AIR 2002; Frank \& Schulze 2000; Schulze \& Frank 2003; see also ADS 2004). Higher wages of officials - through the threat of losing a well-paying job if detected - reduce corruption, but only when officials face the risk of detection and punishment (e.g., Frank \& Schulze 2000, Schulze \& Frank 2003; Azfar \& Nelson 2003; Barr et al. 2003; but see Abbink 2002). The results of Barr et al. (2003) suggest, though, that any increase in wages has to be considerable to effect significant reductions in corruption. The results of Falk \& Fischbacher (2002) and Babicky, Ortmann \& Semerak (2006) strongly suggest that the extent of corruption in a society is a major determinant of corruptibility. And there can be little doubt that skillful design and implementation of laws and regulations can overcome the distant past of a country (e.g., Spagnolo 2004; ADS 2004; Buccirossi \& Spagnolo 2006; Ortmann \& Richmanova 2006).

Experiments are not the panacea that everyone doing research on the determinants of corruption and corruptibility is desperately looking for but they do allow us to address many questions in systematic and relatively low-cost ways. If for example, someone objects to the efficiency gains (or losses) used in a particular experiment, it is easy to test the robustness of the experimental results with another parameterization. If someone objects to the stakes being too small to be telling us something, the experimenter can always scale them up. Even then experiments may be a low-cost means of exploring the effects of detection probabilities, penalty sizes, and their interactions, and the importance of people's perceptions of the pervasiveness of corruption in society.

All things considered, laboratory experiments seem a promising strategy to designing and implementing incentive-compatible and effective anti-corruption measures.

\section{References:}

Abbink, K. (2002), Fair Salaries and the Moral Costs of Corruption. CeDEx Working Paper 2002-5, University of Nottingham.

Abbink, K. (2004), Staff rotation as an anti-corruption policy: an experimental study. European Journal of Political Economy, forthcoming.

Abbink, K. \& Hennig-Schmidt, H. (2002), Neutral versus Loaded Instructions in a Bribery Experiment. Manuscript.

Abbink, K., Irlenbusch, B., \& Renner, E. (2000), The Moonlighting Game. Journal of Economic Behavior and Organization 22, $265-277$. 
Abbink, K., Irlenbusch, B., \& Renner, E. (2002), An Experimental Bribery Game. Journal of Law Economics \& Organization 18, 428 - 454.

Andreoni, J. \& Croson, R. (2004), Partners vs. Strangers; Random rematching in public goods experiments. In: C.R. Plott \& V.L. Smith (Eds.), Handbook of Experimental Results. North-Holland, Amsterdam.

Apesteguia, J., Dufwenberg, M. \& Selten, R. (2003), Blowing the Whistle,

Working Paper 2003-5, Economics, University of Stockholm.

Azfar, O. \& Nelson, W.R.J. (2003), Transparency, wages, and the separation of power. An experimental analysis of the causes of corruption. Working Paper,

U of New York (Buffalo), featured in Transparency International 2004 yearbook.

Babicky, V. \& Ortmann, A. (2005), Fairness in Risky Environments: Theory and Evidence, Mimeo.

Babicky, V., A. Ortmann \& Semerak, V. (2006), Willingness to Contribute When Incomes Are Earned: The Relative Importance of Reciprocity and Inequality Aversion. Mimeo.

Barr, A., Lindelow, M., \& Serneels, P. (2003), To Serve the Community or Oneself: The Public Servant's Dilemma, CSAE WPS 2003-11.

Berentsen, A., Bruegger, E., \& Loertscher, S. (2003), On Cheating and Whisteblowing. Working Paper, Econonomics Department, University of Basel.

Berg, J.E., Dickhaut, J.W., \& McCabe, K.A. (1995), Trust, Reciprocity, and Social History. Games and Economic Behavior 10, 122-142.

Bolton, G. \& Ockenfels, A. (2000), ERC: A Theory of Equity, Reciprocity and Competition, American Economic Review 90, 166-193.

Buccirossi, P. \& Spagnolo, G. (2006), Leniency Policies and Illegal Transactions. Journal of Public Economics (forthcoming)

Charness, G. \& Rabin, M. (2003), Understanding Social Preferences with Simple Tests. Quarterly Journal of Economics 117, 817-869.

Cherry, T.L., Frykblom, P., \& Shogren, J.F. (2002). Hardnose the Dictator. American Economic Review 92, 1218-1221.

Cox, J.C. (2004), How to Identify Trust and Reciprocity, Games and Economic Behavior 46, 260-281.

Dittrich, D.A.V. \& Ziegelmayer, A. (2005), Laboratory Bilateral Gift Exchange: The Impact of Loss Aversion. Mimeo.

Dusek, L., Ortmann, A. \& L. Lizal (2005), Understanding Corruption and Corruptibility Through Experiments. Prague Economic Papers 14, 147-162.

Engelmann, D. \& Strobel, M. (2004), Inequality Aversion, Efficiency, and Maximin Preferences in Simple Distribution Experiments. American Economic Review 94, 857-869.

Falk, A. \& Fischbacher, U. (2000), »Crime« in the lab - detecting social interaction. European Economic Review 46, 859-869.

Fehr, E. \& Schmidt, K. (1999), A theory of Fairness, Competition and Cooperation, Quarterly Journal of Economics 114, 817-868.

Fehr, E., Kirchsteiger, G., \& Riedl, A. (1993), Does Fairness Prevent Market Clearing? An Experimental Investigation, Quarterly Journal of Economics 108, 437-459. 
Fehr, E., Gaechter, S., \& Kirchsteiger, G. (1997), Reciprocity as a Contract Enforcement Device, Econometrica 65, 833-860.

Frank, B. \& Schulze, G.G. (2000), Does economics make citizens corrupt? Journal of Economic Behavior and Organization 43, 101-103.

Gneezy, U. \& Rustichini, A. (2000), Pay Enough or Don't Pay at All. Quarterly Journal of Economics 115, 791-810.

Gueth, W. \& Ortmann, A. (2006), A Behavioral Approach to Distribution and Bargaining. In M. Altman (ed.), Foundations and extensions of behavioral economics: A handbook. Armonk, NY: M.E. Sharpe Publishers, forthcoming.

Guererk, Oe., Irlenbusch, B. \& Rockenbach, B. (2006), The Competitive Advantage of Sanctioning Institutions. Science 312, 108-111.

Harrison, G.W. \& List, J. (2004), Field experiments. Journal of Economic Perspectives 42, 1009-1055.

Hertwig, R. \& Ortmann, A. (2001), Experimental practices in economics: A methodological challenge for psychologists? Behavioral and Brain Sciences 24, 383-403.

Klemperer, P. (2004), Auctions: Theory and Practice. Princeton: Princeton University Press.

Kreps, D.M. (1990), Game Theory and Economic Modelling. Oxford: Oxford University Press.

List, J. (2006), The Behavioralist Meets the Market: Measuring Social Preferences and Reputation Effects in Actual Transactions. Journal of Political Economy (forthcoming).

Lizal, L. \& Ortmann, A. (2003), Designing and Testing Incentive-Compatible and Effective Anticorruption Measures. Grant proposal to GA CR. See home.cerge-ei.cz/ Ortmann/PAPERS/CERGEEIGrantAgCRApplicMarch2003.PDF

Mas-Colell, A., Whinston, M.D., \& Green, J.R. (1995), Microeconomic Theory. Oxford: Oxford University Press.

Milgrom, P. (2004), Putting Auction Theory to Work. Cambridge: University of Cambridge Press.

Ortmann, A. (2003), Bertrand Price Undercutting: A Brief Classroom Demonstration. Journal of Economic Education 34, 21-26.

Ortmann, A. (2004), Corruption Prague. The Prague Post, August 5, A5.

Ortmann, A., Fitzgerald, J., \& Boeing, C. (2000), Trust, Reciprocity, and Social History: A Reexamination. Experimental Economics 3, 81-100.

Ortmann, A. \& Richmanova, J. (2006), How Effective Are Czech Leniency Provisions? An Experimental Investigation. [in prep]

Plott, C. (1997), Laboratory Experimental Testbeds: Application to the PCS Auction. Journal of Economics \& Management Strategy 6, 605-638.

Plott, C. \& Salmon, T.C. (2004), The Simultaneous, Ascending Auction: Dynamics of Price Adjustment in Experiments and in the U.K. 3G Spectrum Auction. Journal of Economic Behavior and Organization 53, 353-383.

Rigdon, M. (2002), Efficiency Wage in an Experimental Labor Market. Proceedings of the National Academy of Sciences of the United States of America 99, 1334813351. 
Roth, A. E. (2002), The Economist as an Engineer: Game theory, Experimentation, and Computation as tools for Design Economics. Econometrica 70, 1341-1378.

Rydval, O. \& Ortmann, A. (2004), How Financial Incentives and Cognitive Abilities Affect Task Performance in Laboratory Settings: An Illustration. Economics Letters 83, 315-320.

Schulze, G.G. \& Frank, B. (2003), Deterrence vs Intrinsic Motivation: Experimental evidence on the determinants of corruptibility. Economics of Governance 4, 143 160.

Spagnolo, G. (2004), Divide Et Impera: Optimal Leniency Policies for Cartel Deterrence. Mimeo.

Treisman, D. (2000), The Causes of Corruption: A Cross-national Study.

Journal of Public Economics 76, 399-457. 